\title{
Role of thyroid scintigraphy vs. fine needle aspiration cytology in the clinical evaluation of solitary thyroid nodule a clinicoradiopathologic study
}

\author{
Khaled El Saban ${ }^{1,2}$, Abdullah Al Zahrani ${ }^{1}$, Hijji Al Sakhri ${ }^{2}$ \\ 1. Faculty of Medicine, Cairo University, Egypt. 2. Al Hada Armed Forced Hospital, Taif, Saudia Arabia \\ Correspondence: Khaled El Saban. Address: Faculty of Medicine, Cairo University, Cairo, Egypt. \\ Email: kelsaban@gmail.com
}

Received: September 25, 2013 Accepted: January 20, 2015

DOI : $10.5430 /$ jst.v5n1p1

URL: http://dx.doi.org/10.5430/jst.v5n1p1

Online Published: January 27, 2015

\begin{abstract}
To asses the value of qualitative and quantitative analysis of the radioisotopes ${ }^{99 \mathrm{~m}} \mathrm{Tc}$ tetrofosmin (Myoview) and ${ }^{99 \mathrm{~m}} \mathrm{Tc}(\mathrm{V})$ DMSA in the evaluation of malignant solitary thyroid cold nodule pre-operatively and to verify their exact value in diagnosis of differentiated thyroid carcinoma. In general there is a 5\%-10\% chance of malignancy in all thyroid nodules for the total population with higher incidence in single cold nodule than in multinodular goiter. The main role of ${ }^{99 \mathrm{~m}} \mathrm{Tc}(\mathrm{V})$ DMSA as a tumor imaging agent is in the diagnosis and follow-up of patients with medullary cancer thyroid. This work included 103 patients, 88 females and 15 males with a mean age of (37.86 \pm 13.59 years). All studied were subjected to history taking, proper clinical examination, thyroid function test profile, thyroid radioisotope imaging $\left({ }^{99 \mathrm{~m}} \mathrm{Tc}\right.$ pertechnetate, ${ }^{99 \mathrm{~m}} \mathrm{Tc}$ tetrofosmin and ${ }^{99 \mathrm{~m}} \mathrm{Tc}(\mathrm{V})$ DMSA thyroid scans) and cytologic assessment of thyroid nodule proved to be cold on conventional thyroid scan. The current study combined both ${ }^{99 \mathrm{~m}} \mathrm{Tc}$ tetrofosmin and ${ }^{99 \mathrm{~m}} \mathrm{Tc}(\mathrm{V})$ DMSA to evaluate thyroid cold nodules and to verify possibility to differentiate between benign and malignant lesions preoperatively and as confirmed on cytology of lesions obtained by fine needle aspiration cytology (FNAC) modality. Our results showed that ${ }^{99 \mathrm{~m}} \mathrm{Tc}$ pertechnetate scan alone is not a reliable diagnostic tool to differentiate between benign and malignant thyroid nodules and that high early myoview uptake in the cold nodule is not specific for malignancy, it is also concluded that both ${ }^{99 \mathrm{~m}} \mathrm{Tc}$ tetrofosmin and ${ }^{99 \mathrm{~m}} \mathrm{Tc}(\mathrm{V})$ DMSA thyroid scans are valuable diagnostic tools when combined together.
\end{abstract}

\section{Keywords}

${ }^{99 \mathrm{~m}} \mathrm{Tc}-$ Myoview, ${ }^{99 \mathrm{~m}} \mathrm{Tc}-(\mathrm{V})$ DMSA, Fine needle aspiration cytology, Cold thyroid nodule

\section{I ntroduction}

The role of thyroid scintigraphy in the initial evaluation of the thyroid nodule has been questioned by several investigators. However, thyroid scanning remains critical for the determination of autonomously functioning thyroid tissue ${ }^{[1]}$. On the other hand, most benign and virtually all malignant neoplastic or nodular goitrous thyroid tissue concentrate ${ }^{99 \mathrm{~m}} \mathrm{Tc}$ pertechnetate, or radioactive iodine less avidly than adjacent normal thyroid tissue. This results in a "cold" appearance on the scintigram ${ }^{[2]}$. Many attempts have been made to find reliable, non-invasive tests to differentiate malignant from benign lesions. 
Although fine needle aspiration has been used for more than 25 years, its role is still somewhat controversial and highly dependent on technique and on the experience of the pathologist.

Many tumor seeking radiopharmaceuticals have been tried, such as selenium -75 (Se-75), Cs-131 and gallium -67(Ga-67) citrate, but the sensitivity has never been high enough ${ }^{[3]}$.

Thallium-201 $\left(\mathrm{Tl}^{201}\right),{ }^{99 \mathrm{~m}} \mathrm{TC}-\mathrm{methoxy}$ isobutyl isonitrile $\left({ }^{99 \mathrm{~m}} \mathrm{Tc} \mathrm{MIBI}\right),{ }^{99 \mathrm{~m}} \mathrm{Tc}$ tetrofosmin and ${ }^{99 \mathrm{~m}} \mathrm{Tc}$ furifosmin radiopharmaceuticals were first developed through extensive- research efforts for cardiac imaging followed by accidental discovery of their accumulatation in tumors $1 .{ }^{99 \mathrm{~m}} \mathrm{Tc}$-pentavalent dimercaptosuccinic acid $\left({ }^{99 \mathrm{~m}} \mathrm{Tc}(\mathrm{V}) \mathrm{DMSA}\right)$ was first introduced as renal imaging agent ${ }^{[4]}$, believed that increased blood flow to malignant lesions and $\mathrm{pH}$ of the tumors are parameters that may have relevance to accumulation of ${ }^{99 \mathrm{~m}} \mathrm{Tc}(\mathrm{V})$ DMSA in metabolically active tumor cells ${ }^{[5]}$. The main role of ${ }^{99 \mathrm{~m}} \mathrm{Tc}(\mathrm{V})$ DMSA as a tumor imaging agent is in the diagnosis and follow-up of patients with medullary cancer thyroid ${ }^{[6]}$.

The aim of the work was to assess the diagnostic value and accuracy of radioisotope thyroid imaging in the evaluation of thyroid nodules in general, and thyroid malignant nodules in particular, and comparing this with FNAC.

\section{Patients and method}

The current study included 103 patients ( 15 males and 88 females), their ages ranging from 15-73 years old with a mean of $37.86 \pm 13.59 \mathrm{y}$, who were referred from medical and endocrine clinics to nuclear medicine department at Al Hada Armed Forced Hospital for scintigraphy, in the period from May to November 2013. Patients were grouped into 2 main groups: group 1: with benign lesions and comprised 80 patients, and group II: with malignant lesions and included 23 patients (see Figure 1). The institutional review board approved our study and was made aware of the additional radiation dose. All patients consented to be subjected to the current study with full explanation of the protocol and they were informed of the radiation dose and its risks. They also consented to the use of their data for future retrospective research.

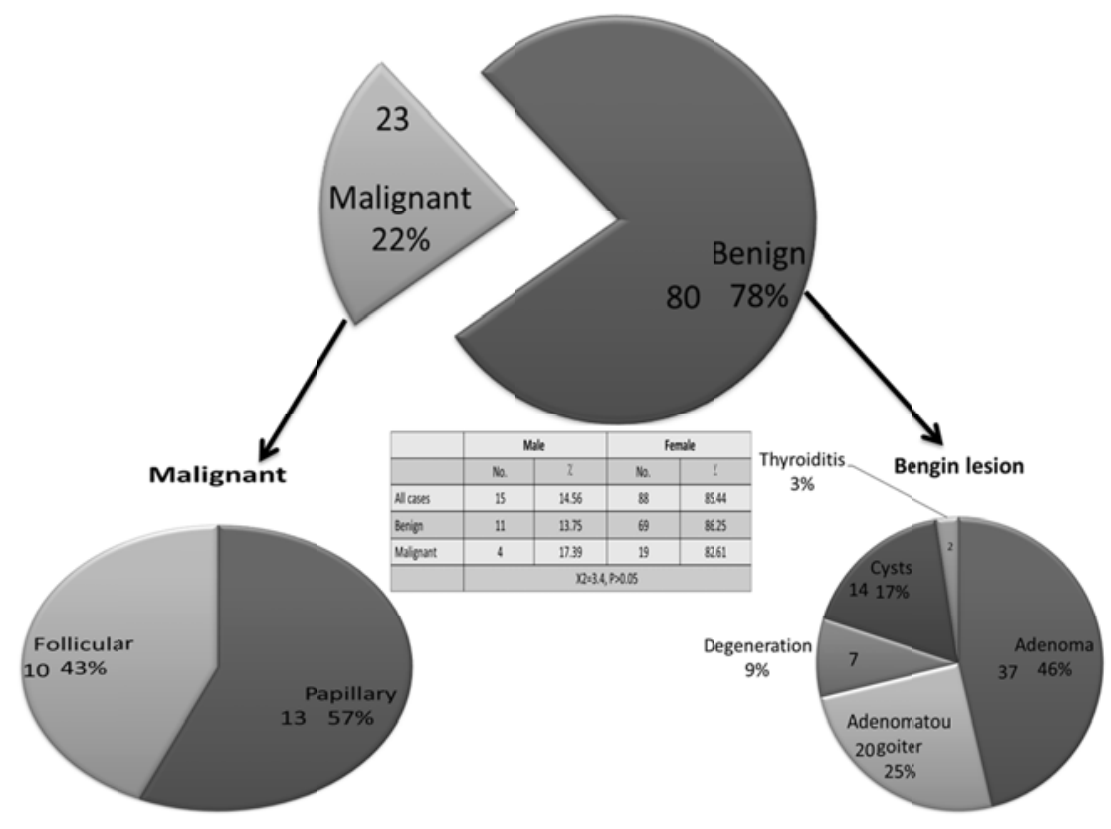

Figure 1. Distribution of patients According to nature of Lesions 


\section{Eligibility criteria for inclusion in the study were:}

A single palpable thyroid nodule, absence of toxicosis manifestations clinically with normal thyroid hormonal profile, the palpable nodule proved to be cold on conventional ${ }^{99 \mathrm{~m}} \mathrm{Tc}$ scan, and lastly with normal scintigraphic appearance of the contralateral thyroid lobe.

In addition to conventional ${ }^{99 \mathrm{~m}} \mathrm{Tc}$ pertechnetate thyroid scan, and thyroid ultrasound all patients were subjected to: Proper history taking with special concern on thyroid symptomatology, Full clinical examination with special emphasis on clinical examination of thyroid and cervical lymph nodes, ${ }^{99 \mathrm{~m}} \mathrm{Tc}$-Tetrofosmin (Myoview) thyroid scan, ${ }^{99 \mathrm{~m}} \mathrm{Tc}(\mathrm{V}) \mathrm{DMSA}$ thyroid scan, and histopathologic assessment of single thyroid nodule proved to be cold on conventional thyroid scan.

\section{${ }^{99 \mathrm{~m}}$ Tc pertechnetate:}

Patients were injected intravenously with $185 \mathrm{MBq}$ (Mega Bequerel) of free ${ }^{99 \mathrm{~m}} \mathrm{Tc}$ pertechnetate. Fifteen to twenty minutes later they were imaged on dual head Siemens gamma camera (e-cam), using single detector fitted with a large field, low energy, high resolution collimator. After adjusting the energy peak at $140 \mathrm{KeV}$ with a window $20 \%$, images were acquired in anterior position for $300 \mathrm{sec}$. A mark was placed on suprasternal notch to assess retrosternal extension.

\section{${ }^{99 m}$ Tc-Tetrofosmin (Myoview):}

Forty-eight hours after conventional ${ }^{99 \mathrm{~m}} \mathrm{Tc}$ pertechnetate thyroid scan ${ }^{99 \mathrm{~m}} \mathrm{Tc}$ Tetrofosmin scan was done.

- Kit preparation: ${ }^{99 \mathrm{~m}} \mathrm{Tc}-\mathrm{Tetrofosmin}$ was prepared by adding $2000 \mathrm{MBq}$ of free ${ }^{99 \mathrm{~m}} \mathrm{Tc}$ to the already available vial of Tetrofosmin powder followed by gentle shaking of the vial for seconds. Doses were withdrawn 5-10 minutes after preparation.

- Patients were injected 555-740 MBq intravenously. Images were acquired $5 \mathrm{~mm}$. and 1 hour post injection on the same dual head Siemens gamma camera (e-cam) using the anterior detector, equipped with low energy, high resolution collimator. Each image was acquired for $300 \mathrm{sec}$.

- Image processing: A region of interest (ROI) around the imaged cold nodule by free ${ }^{99 \mathrm{~m}} \mathrm{Tc}$ and another (ROI) around the contralateral thyroid tissue are drawn. The count of each (ROI) was calculated to get the following ratios:

$$
\begin{gathered}
E R=\text { Early ratio }=\frac{\text { Counts of ROI in the lesion }}{\text { Counts of ROI in the other lobe }}(\text { in early image }) \\
D R=\text { Delayed ratio }=\frac{\text { Counts of ROI in the lesion }}{\text { Counts of ROI in the other lobe }}(\text { in delayed image }) \\
R I=\text { Retention Index }=\frac{D R-E R}{E R} \times 100
\end{gathered}
$$

\section{${ }^{99 \mathrm{~m}}$ Tc (V) DMSA:}

- Preparation of ${ }^{99 \mathrm{~m}} \mathrm{Tc}(\mathrm{V})$ DMSA: $7 \%$ sodium bicarbonate is initially prepared by mixing of $8.4 \%$ sodium bicarbonate with $5 \%$ sodium bicarbonate in a ratio of 7:5 respectively. ${ }^{99 \mathrm{~m}} \mathrm{Tc}(\mathrm{V})$ DMSA is then prepared by the 
addition of $0.2 \mathrm{ml}$ of $7 \%$ sodium bicarbonate to a vial containing DMSA powder and following mixing of the vial components; ${ }^{99 \mathrm{~m}} \mathrm{Tc}$ pertechnetate is then added with the indicated activity and volume.

- Each patient was injected 555-740 MBq intravenously, early image was acquired 5-mm. post injection and late image was acquired 1 hour later on the same dual-head ADAC gamma camera. Study was performed $48 \mathrm{hrs}$ following the ${ }^{99 \mathrm{~m}} \mathrm{Tc}-$ Tetrofosmin scan. A $300 \mathrm{sec}$. Acquisition time was used.

- Imaging processing: A ROI was drawn around each lobe and differential counts were calculated to get ER, DR and RI.

\subsection{I mage interpretation}

Images were interpreted by 2 independent observers and were classified in early images for (V)DMSA only and early and late images for Tetrofosmin as:

$\mathrm{A}=$ activity less than the surrounding normal thyroid tissue.

$\mathrm{B}=$ activity same as the surrounding normal tissues.

$\mathrm{C}=$ more active (hot) than the surrounding thyroid tissue with either wash-out in the late image, retention or partial wash-out.

\section{Fine needle nspiration cytology}

Conventional smears fine needle nspiration cytologys (FNACs) were performed with 23 to $27 \mathrm{G}$ needle under sonographic or manual guidance. The material was immediately fixed in 95\% ethyl alcohol and stained with Papanicolaou stain.

The cytological diagnoses were classified according to the British Thyroid Associations "Guidelines for Management of Thyroid Cancer" into five cytological groups of classification for nodular lesions ${ }^{[7]}$ : THY1, inadequate; Thy2, benign, including colloid nodule (CN), thyrocytic hyperplasia without nuclear atypia (THWNA) and thyroiditis (TH); Thy3 or follicular proliferation (FP) with follicular neoplasm not otherwise specified (FN) and oxyphilic follicular neoplasm (OFN); Thy4, suspicious including follicular lesion with nuclear pleomorphism (FLWNP) including the three scenarios mentioned by Rossi et al., (2012) ${ }^{[8]}$; Thy5, malignant including papillary carcinoma (PC) and medullary carcinoma (MTC).THY1 was excluded from the study.

\subsection{Surgical management}

Surgery was performed in cases of malignant or suspicious neoplasms diagnosed on the basis of the preoperative FNAC or to remove a nodular goiter for cosmetic or functional reasons. Regarding the surgical management, the operative strategy included a total thyroidectomy (TT) and in all patients with multinodular goiters and in all patients with cytological diagnosis of malignancy. Central neck dissection and lateral neck dissection were performed only in patients proven positive for lymph node metastasis or in those with poor prognostic factors. Lobectomy plus isthmusectomy, diagnostic lobectomy ${ }^{[9]}$ was advised as the first step in patients with a single lesion showing either a clinical picture and/or a cytological diagnosis of Thy 3 and Thy4 lesion. If the final histology yielded a diagnosis of malignant neoplasm, subsequent completion was carried out.

\subsection{Statistical method}

Data were statistically described in terms of mean +standard deviation (SD), median and range, or frequencies (number of cases) and percentages when appropriate. Comparison of numerical variables between the study groups was done using unpaired Student $t$ test. For comparing categorical data, Chi square $\left(\chi^{2}\right)$ test was performed. Exact test was used instead when the expected frequency is less than 5. Multivariate analyses were done using two steps first correlation matrix 
followed by regression analysis. $P$ values less than .05 was considered statistically significant. All statistical calculations were done using computer programs SPSS (Statistical Package for the Social Science; SPSS Inc., Chicago, IL, USA) version 15 for Microsoft Windows.

\section{Results}

I - Demographic Data: Including grouping of the current study, Age, Sex, Type of pathology and malignancy grading are shown in Figure 1 and Table 1.

II - Scintigraphic findings are shown in Figures 2-5.

Table 1. Distribution of patients with malignant lesion according to grade of malignancy

\begin{tabular}{|c|c|c|c|c|c|c|}
\hline & \multicolumn{2}{|c|}{ Grade I } & \multicolumn{2}{|c|}{ Grade II } & \multicolumn{2}{|c|}{ Grade III } \\
\hline & No. & $\%$ & No. & $\%$ & No. & $\%$ \\
\hline Follicular Ca. & 7 & 87.5 & 3 & 75 & 3 & 27.3 \\
\hline Papillary Ca & 1 & 12.5 & 1 & 25 & 8 & 72.7 \\
\hline Total & 8 & 34.8 & 4 & 17.4 & 11 & 47.8 \\
\hline
\end{tabular}

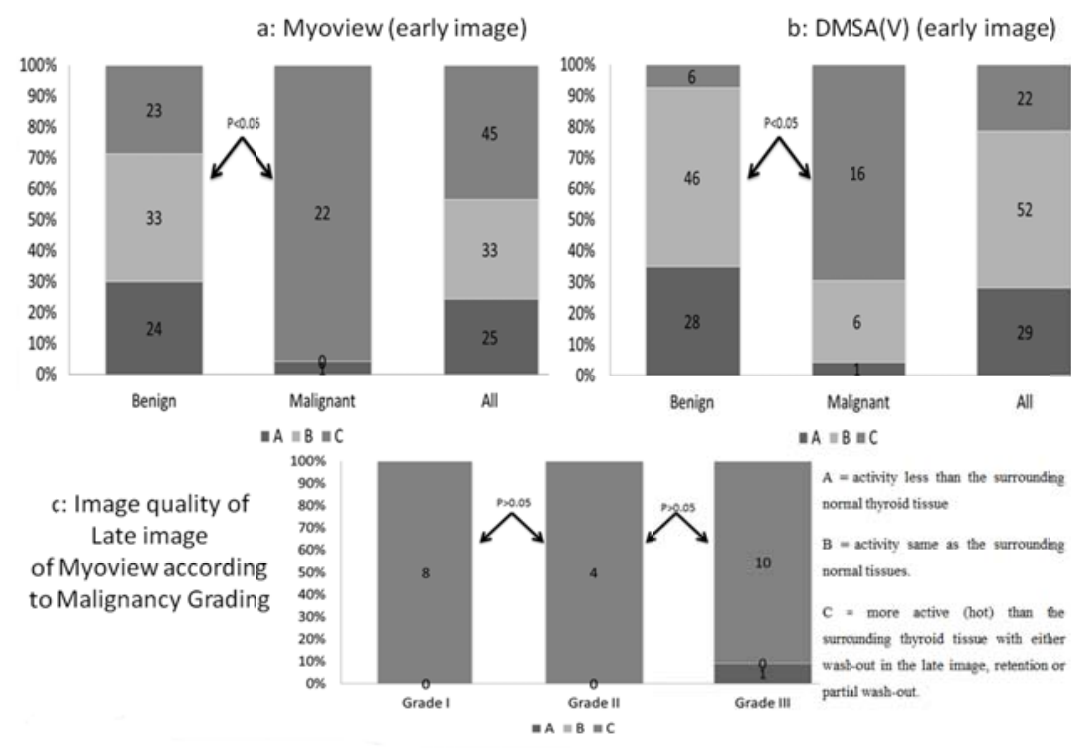

Figure 2. Image quality of Myoview and DMSA(V) in the studied groups

The following results were obtained: All patients had normal thyroid function confirmed by hormonal measurements and cold solitary thyroid nodule, which was evaluated by pertechnetate scanning. The early phase scintigraphy of ${ }^{99 \mathrm{~m}} \mathrm{Tc}$ Myoview showed high uptake in 45 patients ( 22 were malignant and 23 were benign by FNAC examination) (see Figure 2a). While early phase scintigraphy of ${ }^{99 \mathrm{~m}} \mathrm{Tc}$ (v) DMSA showed high uptake in 22 patients ( 16 were malignant and 6 were benign by FNAC examination) (see Figure 2b). On the other hand, in late myoview images high uptake was noted in all grades of malignancy. Quantitative analysis showed high retention index of Myoview in malignant lesions compared to benign lesions (see Figure 3a). Using a receiver operating curve, a cut-off point $>14 \%$ could separate between benign and malignant lesions (see Figure 4). On the other hand, RI was highest in the high grade malignancy (39.85 \pm 28.86 ) (see Figure $3 \mathrm{~b}$ ) compared to lowest in low grade $(-19.5 \pm 16.1)$. This was confirmed by strong linear regression analysis $(r=0.70869, P<.01)$, between grading and myoview retention index (RI). In addition the multivariate regression revealed a significant predictable by which malignant lesions could be detected as seen Table 2 , with the note that $r^{2}=63.1 \%$, i.e. any change in this equation will result in 63.1 percent change in the accuracy of detection with standard error of estimation 
0.2964. This error could be explained by Figure 5 which revealed that if the malignant lesion was follicular the false negative increases.

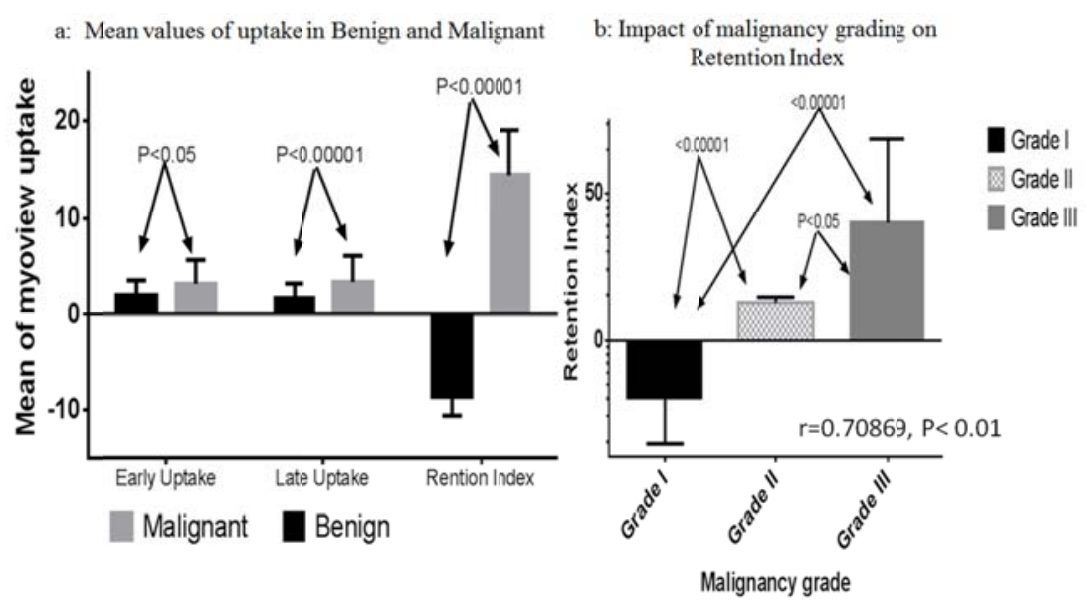

Figure 3. Quantitative Assessment of Tetrofosmin uptake in the studied groups

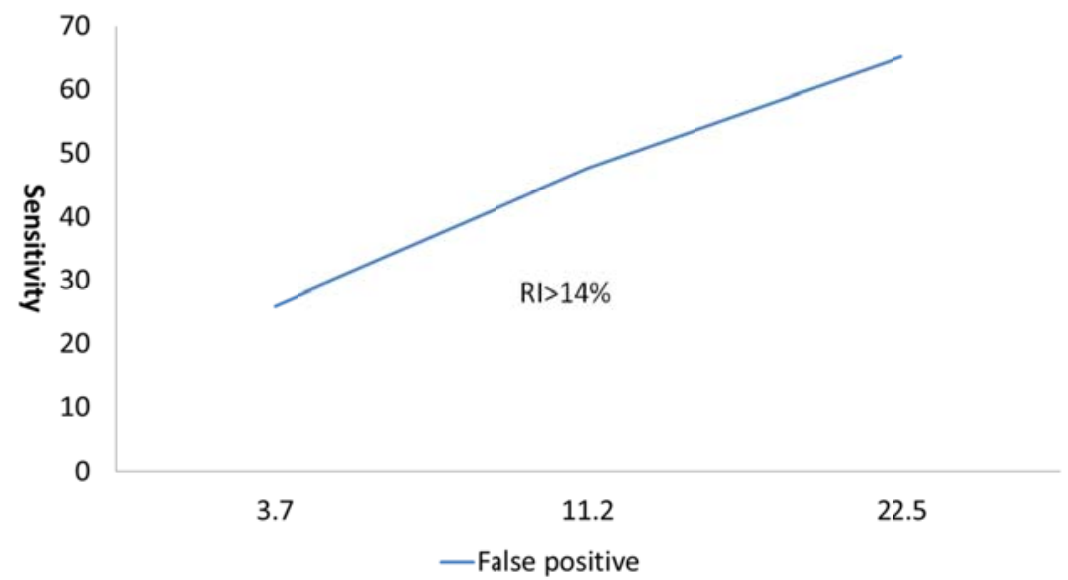

Figure 4. Cut-off values of retention index of tetrofosmin to detect malignancy

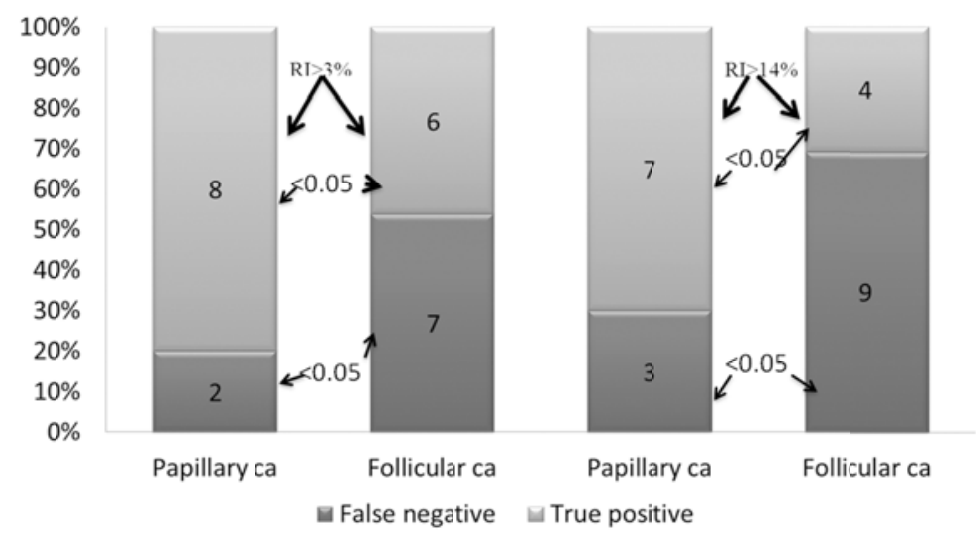

Figure 5. Impact of pathology on retention index of tetrofosmin 
Table 2. Multivariate analysis to predict presence of malignancy

\begin{tabular}{lllll}
\hline & Slope (B) & SEE & $\boldsymbol{P}$ & $\boldsymbol{r}^{2}$ \\
\hline Myoview image quality & 0.2627 & 0.0703 & $<.001$ & $36.8 \%$ \\
Myoview RI & 0.0042 & 0.0023 & $=.05$ & $11.86 \%$ \\
DMSA (V) & 0.007 & 0.004 & $>.05$ & $11.23 \%$ \\
\hline
\end{tabular}

Note. With intercept $=-.03272$, SEE $=0.2964$, Multiple $r=0.7943, r^{2}=63.1 \%, P<.01$

\section{Discussion}

The current study revealed that absence of intense tracer uptake in single thyroid cold nodule in ${ }^{99 \mathrm{~m}} \mathrm{Tc}$ pertechnetate and both early and late ${ }^{99 \mathrm{~m}} \mathrm{Tc}$ tetrofosmin and ${ }^{99 \mathrm{~m}} \mathrm{Tc}(\mathrm{V})$ DMSA is highly sensitive and predictive but moderately specific in exclusion of malignant lesions. In addition, high early uptake of myoview together with high retention index increase the probability of malignancy using a cut-off $>14 \%$ but still not enough to differentiate between malignant lesions and some benign adenomas. High early Myoview uptake together with high retention index of myoview and high early (V) DMSA uptake are strongly positive for high grade malignancy

The initial medical evaluation of patients with thyroid nodules should effectively select patients who would likely to benefit from surgery (who are likely to have malignancy) versus patients who should be medically managed conserveatively and put under observation and regular check-up visits in endocrinology (or thyroid) clinic.

Three main modalities of investigation are available, namely isotope thyroid scanning, ultrasound scanning and fine needle aspiration cytology. While all these tests have appropriate indications, utility and limitations, no single test can provide alone a practical approach to the evaluation of the thyroid nodule ${ }^{[10,11]}$.

Various radiopharmaceuticals have been employed to image tumors. $\mathrm{Tl}^{201}$ had been reported to accurately differentiate benign from malignant thyroid nodules, although some authors have questioned the value of the procedure ${ }^{[1]}$.

On the other hand, ${ }^{99 \mathrm{~m}} \mathrm{Tc}$ MIBI and ${ }^{99 \mathrm{~m}} \mathrm{Tc}$ tetrofosmin (Myoview) have shown better uptake than $\mathrm{Tl}^{201}$ in certain neoplasms. Biochemical and cellular pharmaceutical studies had suggested that these lipophilic cations were sequestered in mitochondria in response to the plasma and mitochondrial membrane potential ${ }^{[2-4]}$.

Therefore, it can be assumed that malignant thyroid nodules have an increased ability to accumulate and retain ${ }^{99 \mathrm{~m}} \mathrm{Tc}$ Myoview and ${ }^{99 \mathrm{~m}} \mathrm{Tc}$ MIBI because of an altered membrane potential and increased metabolic demands ${ }^{[3,4]}$.

Hirano et al, (1995) ${ }^{[5]}$ have postulated that (V) DMSA resembles the phosphate ion, and suggested that this is the mechanism by which ${ }^{99 \mathrm{~m}} \mathrm{Tc}(\mathrm{V})$ DMSA accumulates in tumor as it is taken by the tumor cells in a similar manner to phosphate molecule with increased protein metabolism. Others postulated its affinity to high blood supply to the tumors, but nothing was proved to accumulate (V) DMSA except medullary carcinoma of the thyroid so it is used in its diagnosis and follow up ${ }^{[11-13]}$.

\section{Inter-relationship between the available data of the current study:}

If this is applied to ${ }^{99 \mathrm{~m}} \mathrm{Tc}(\mathrm{V}) \mathrm{DMSA}$, it is revealed that absence of intense tracer accumulation is highly sensitive in diagnosis of benign lesions (92\%), yet, it evidently lacks specificity. While the intense tracer accumulation of this tracer (quality $\mathrm{C}$ ) in solitary thyroid nodule lacks sensitivity and specificity in diagnosis of malignant thyroid nodules ( $61.5 \%$ and $62 \%$ respectively). 
If the present study adds these data together, the absence of intense tracer accumulation in both ${ }^{99 \mathrm{~m}} \mathrm{Tc}$ tetrofosmin and

${ }^{99 \mathrm{~m}} \mathrm{Tc}$ (V) DMSA scans can combine both high sensitivity and specificity (92\% and $95.8 \%$ respectively).

So a nodule that does not accumulate both tracers is most likely benign. On the other hand, the active tracer uptake in this nodule (quality $\mathrm{C}$ ) lacks both sensitivity and specificity in diagnosis of malignancy, attributed to avidity of follicular adenoma to both tracers.

Again Mezosi el al, (1999) ${ }^{[2]}$, reported that Myoview scan is more useful in differentiating degenerative disease from neoplastic thyroid disease, rather than differentiating benign from malignant nodule. They attributed this by the finding of high uptake of Myoview in adenomas, a finding similar to the current study, which showed the same. The two studies concluded lower specificity and positive predictive value for differentiation between benign and malignant nodule. This is why the current study proceeds to use the regression analysis, in a trial to separate between malignant and benign nodules. This logistic regression concluded the necessity of presence of quality C scan in both Myoview and (V) DMSA early imaging together with high retention index $(>14 \%)$ to separate between both with higher sensitivity (75\%) and high specificity (100\%). Quality C scan in (V) DMSA means high vascularity in the nodule while quality C Myoview scan means high metabolic activity in addition to this high retention index which means dense mitotic activity in this nodule as stated by Schomacker and Schicha (2000) ${ }^{[14]}$.

On the other hand, the current study revealed high uptake (C) in high grade malignancy with lower degree of uptake in low grade malignancy which is attributed to the dense mitochondrial activity in higher $\mathrm{Na}^{+} / \mathrm{Ca}^{++}$exchange channels in the cell membrane as stated by Arab et al $\left(1998\right.$ and 1999) ${ }^{[15,16]}$. This is why the current study revealed low sensitivity to detect malignancy and in addition the use of the suitable cut-off of retention index mean $+1.5 \mathrm{SD}(14 \%)$.

\section{Conclusion}

From this, the current study concluded that Myoview uptake in cold nodule is suitable in assessment of grading of malignant tumors rather than differentiation between malignant and benign lesion. To do the later it requires both Myoview and (V) DMSA and use of the regression equation.

\section{References}

[1] Tanju T, Ozker, Kabasakal L, Kermaz B. The role of ${ }^{99 m}$ Tc MIBI and T1 201 in diagnosis of thyroid cold nodules. Eur J Nucl Med. 2000; 27: 713-720.

[2] Mezosi E., Bajnok L., Gyory F., Varga J., Sztojka I. Szabo J., et al. The role of ${ }^{99 \mathrm{~m}}$ Tc MIBI scintigraphy in the differential diagnosis of cold thyroid nodules. Eur J. Nucl Med. 1999; 26: 790-803.

[3] Lind P., Hans JG., Rikosch P, and Molnar M. ${ }^{99 \mathrm{~m}}$ Tc tetrofosim whole body scintigraphy in the follow up of differentiated thyroid cancer. 1997; 38: 348-352.

[4] Yokoyama A., Hata N. and Saj H. Chemically designed ${ }^{99 \mathrm{~m}}$ Tc radiopharmaceuticals for the tumor diagnosis. J. Nucl. Med. 1981; 22: 69.

[5] Hirano T., Otake H., Yashida I. And Endo K. Primary lung cances SPECT imaging with ${ }^{99 m}$ Tc (V) DMSA. J Nud Med. 1995; 36 : 202-207.

[6] Clarke SE, Lazarus CR., Maisey MN. Experience in imaging of medullary thyroid carcinoma using ${ }^{99 m}$ Tc (V) DMSA. H ford Hosp Med J. 1989; 37: 167-168.

[7] Ardito G, Rossi ED, Revelli L, Moschella F, Giustozzi E, Fadda G, et al. The role of fine-needle aspiration performed with liquid-based cytology in the surgical management of thyroid lesions. In Vivo. 2010; 24(3): 333-7. PMid:20555009

[8] Rossi ED1, Zannoni GF, Moncelsi S, Stigliano E, Santeusanio G, Lombardi CP, et al. Application of liquid-based cytology to fine-needle aspiration biopsies of the thyroid gland. Front Endocrinol (Lausanne). 2012; 16(3): 57.

[9] Ardito G, Revelli L, Moschella F, Fadda G, Ardito F, Galata G, et al. Diagnostic lobectomy for unilateral follicular nodules of the thyroid gland. 2004; Surg Today 34(6): 557-559. PMid:15170558 http://dx.doi.org/10.1007/s00595-004-2754-0

[10] Mazzaferri EL. Management of a solitary thyroid nodule. N-Engl J Med. 1993: 328- 553. 
[11] Mazzaferri EL, Jhiang Sm. Long term impact of initial surgical and medical therapy on papillary and follicular thyroid cancer. Am J Med. 1992; 97: 418. http://dx.doi.org/10.1016/0002-9343(94)90321-2

[12] Foldes I., Lavery A, Stotz G. Comparative scanning of thyroid nodules with technetium ${ }^{99 \mathrm{~m}}$ pertechnetate and ${ }^{99 \mathrm{~m}}$ Tc MIBI. Eur J Nucl Med. 1993; 20: 330-333. PMid:8387921 http://dx.doi.org/10.1007/BF00169809

[13] Sognadele BS., Minderman H., Alessi MA., Yin A. ${ }^{99 \mathrm{~m}}$ Tc tetrofosmin mechanism of uptake into isolated rat ventricular myocytes and subcellular localization. J. Nucl Cardiol. 1994; 2: 317- 326.

[14] Schomacker, Schicha. Clinical nuclear medicine. Eur J Nucl Med. 2000; 27: 1845-1863. PMid:11189949

[15] Arab AS., Koizumi K., Toyamak Arai T., Araki T. Technetium- $-{ }^{99 \mathrm{~m}}$ tetrofesmin, ${ }^{99 \mathrm{~m}} \mathrm{Tc}$ MIBI and T1 uptake in rat myocardial cell. J. Nucl Med. 1998; 39: 266-271.

[16] Arab AS., Koizumi K., Toyamak Arai T., Araki T. Effects of ion channel modulators in the influx and efflux of ${ }^{99 \mathrm{~m}}$ Tc MIBI Ann Nucl Med. 1999; 13: 27-32. http://dx.doi.org/10.1007/BF03165424 